Original article

\title{
The effects of disease severity, use of corticosteroids and social factors on neuropsychiatric complaints in severe acute respiratory syndrome (SARS) patients at acute and convalescent phases
}

\author{
Bun Sheng ${ }^{\text {a,* }}$, Sammy Kin Wing Cheng ${ }^{b}$, Kwok Kwong Lau ${ }^{\text {a }}$, \\ Ho Lun Li ${ }^{a}$, Eric Lok Yiu Chan ${ }^{c}$ \\ ${ }^{a}$ Department of Medicine and Geriatrics, Princess Margaret Hospital, Lai Chi Kok, Kowloon, Hong Kong \\ ${ }^{b}$ Consultation and Liaison Psychiatry Team and Clinical Psychology Service Unit, Kwai Chung Hospital, Hong Kong \\ ${ }^{c}$ Department of Medicine and Geriatrics, Caritas Medical Centre, Hong Kong
}

Received 12 November 2003; revised and accepted 11 May 2004

Available online 16 September 2004

\begin{abstract}
Objective. - To evaluate the effects of disease severity, corticosteroids and social factors on neuropsychiatric complaints in severe acute respiratory syndrome (SARS) patients, both during acute and convalescent phases.

Subjects and methods. - Self-administered mail questionnaires survey to 308 SARS patients after discharging from hospital. Both patients and their families were asked about symptoms related to various neuropsychiatric domains, and the questions covered both acute and convalescent phases.

Results. - Among the 102 (33\%) valid replies, 65\% had strong symptoms in convalescent phase as indicated by GHQ28 score $\geq 5$. In multiple linear regression analysis, use of pulse steroid and total dosages of pulse steroid during hospitalisation were predictive for anxietydepression, psychosis and behavioural symptoms in acute phase, the effects persisted in convalescent phase. Disease severity had direct correlation with symptoms in all neuropsychiatric domains at acute phase and anxiety-depression and cognition at convalescent phase. Health care workers had more neuropsychiatric complaints in both phases. Severity of symptoms, corticosteroids and social factors explained about half of the variances $\left(R^{2}=52\right)$ in anxiety-depression at acute phase and $33 \%$ at convalescent phase.
\end{abstract}

Conclusion. - Severe disease, high dose corticosteroids and being health care workers were independent predictors of neuropsychiatric complaints in both acute and convalescent phases.

(c) 2004 Elsevier SAS. All rights reserved.

Keywords: Severe acute respiratory syndrome; Steroids; Health care workers; Mental disorders

\section{Introduction}

Since Spring 2003, severe acute respiratory syndrome (SARS) prevailed in China and Hong Kong [4,28]. The whole world was under threat by this highly contagious, devastating viral pneumonia. The disease, which was later found to be due to a new coronavirus [21,22], took away 299 lives in Hong Kong, and 916 worldwide [25]. Princess Margaret Hospital has been designated to receive SARS patients in the early phase of the epidemic. Five hundred and ninety eight out of 1755 SARS patients were admitted into the hospital.

\footnotetext{
* Corresponding author.

E-mail address: shengbun@ hotmail.com (B. Sheng).
}

During the initial stage, much attention has been drawn to the definition, diagnosis and treatment of SARS. As time went on, many other complications of the disease and also of the treatment became apparent. Neuropsychiatric manifestations were among these complications. We saw patients attempted suicide during quarantine period, delirium was not uncommon [5], and many were anxious and worrying. Furthermore, many patients had neuropsychiatric symptoms persisted after discharge, and some patients developed new symptoms in the recovery phase. SARS had strong reasons to cause adverse neuropsychiatric impacts. It affected the whole family, either as being patients or patient contacts that required quarantine observations. High dose corticosteroids we used in the treatment, especially in the early epidemic when our knowledge on SARS was limited, had exposed patients to 
possible steroid related adverse effects. SARS was also a lethal disease and many patients required mechanical ventilation in intensive care units (ICU). Because of the contagious nature and unknown route of transmission, the disease carried a negative stigmatization. The purpose of our study is to evaluate the relative contributions of disease severity, use of corticosteroids and social factors on the symptoms in various neuropsychiatric domains in acute and convalescent phases.

\section{Subjects and methods}

\subsection{Survey method}

We conducted a questionnaire survey to 308 SARS victims who attended the Princess Margaret Hospital SARS follow up clinic from 15 April-15 May 2003. The questionnaires were administered by mail in early June 2003 with return envelopes. To encourage reply we gave phone call to all patients before sending them questionnaires. One of the questionnaires, the SARS Neuropsychiatric Symptoms Checklist (NPSC), was specifically designed to evaluate the neuropsychiatric complaints after SARS according to our initial experiences [5]. It consisted of 25 items covering six neuropsychiatric domains of interest (see Appendix for questionnaire), namely cognition (Q1-4), mania (Q5-8), depression (Q9-15), anxiety (Q16-18), psychosis (Q19-21) and behavioural symptoms (Q22-25). The items were scored on a four-point ordinal scale with '0' representing 'none' and ' 3 ' 'always'. This questionnaire was duplicated into four. Two questionnaires were administered by patients and two were administered by their families. The first set was rated to the best of their recall during hospital stay (at acute phase), and the second set was rated according to their present state (at convalescent phase). The questionnaires administered by family members served to evaluate the reliability of the information provided by the patient. Severity of the SARS symptoms was recorded on a separate eight-item checklist using an ordinal scale from 0 to 3 , which gave a maximum possible score of 24. We also included General Health Questionnaire 28 (GHQ28) as a screening tool for psychological well being at convalescent phase [3]. The study was approved by local ethics committee, and informed consent was obtained from every participant.

\subsection{Reliability and consistency of NPSC}

We performed the Pearson correlation between the patient rated questionnaire and family rated questionnaire on each neuropsychiatric domain. Using the strength assessment suggested by Munro [18], moderate strength correlations were assigned to cognition, depression, psychosis and mania while the correlation strength in anxiety was low. The items on behavioural symptoms were not well correlated. We believed families were difficult to observe the behavioural changes because they were not allowed to have direct patient contact during hospital stay. Cronbach $\alpha$, which indicated the lower bound of inter-item correlation in a cluster of items [8], revealed a good internal consistency in the cognition $(\alpha=0.70)$, anxiety $(\alpha=0.78)$ and depression $(\alpha=0.83)$. The questionnaire performance in convalescent phase was significantly correlated with GHQ28 $(r=0.64, P<0.001)$.

\subsection{Exploratory factor analysis on NPSC at acute and convalescent phases}

For the acute phase, we extracted six components in the initial principle component analysis with eigen value more than one [7]. According to the clustering of items at a factor loading cutoff of 0.4 , we reconstructed the factor domains into anxiety-depression, psychosis, positive attitude, mania, cognition and behavioural symptoms, respectively. The common factors explained $65.3 \%$ of the total variances in the items. The factor structure at convalescent phase was slightly different from above. Instead of the six domains in acute phase, we constructed four common factors, namely anxietydepression, positive psychological well-being, cognition and mania, which altogether explained $63 \%$ of the total variances in the items at convalescent phase.

\subsection{Relationship between disease severity, use of corticosteroids, social factors and the neuropsychiatric symptoms of SARS patients in acute and convalescent phases}

Factors scores calculated in each domain were used as the neuropsychiatric outcomes of interest for each patient. Effects of representative variables chosen for SARS severity, dosage and form of corticosteroids and social factors on the outcome variables were first examined in the univariate analysis, covariates were then tested in the multiple linear regression model. We used the SPSS software in statistical analysis [26]. All tests were two-end conducted at 0.05 level of significance.

\section{Results}

We received 102 valid replies, the response rate was $33 \%$. The demography, social backgrounds and the clinical features of the replied were tabulated in Tables 1 and 2, respectively. The mean duration from hospital discharge to questionnaire administration was 42 days (range 26-86). Sixty-six patients scored five or above in GHQ28, a cutoff level which indicated severe symptoms and possible benefit from psychiatric consultation.

\subsection{Medications given for SARS}

All but one patient received ribavirin and corticosteroids. Most patients received intravenous ribavirin at $1200 \mathrm{mg}$ daily 
Table 1

Demography and social background of SARS survivors

\begin{tabular}{|c|c|c|}
\hline & $\begin{array}{l}\text { Background } \\
\text { information }\end{array}$ & $N=102$ \\
\hline \multicolumn{2}{|l|}{ Age (mean \pm S.D.) } & $37.6 \pm 12.4$ \\
\hline \multicolumn{2}{|l|}{ Male $(\%)$} & $35(34.3)$ \\
\hline \multicolumn{3}{|l|}{ Marital status (\%) } \\
\hline & Single & $34(33.3)$ \\
\hline & Married & $61(59.8)$ \\
\hline & Co-inhabit & $2(2)$ \\
\hline & Separated & $1(1)$ \\
\hline & Widowed & $3(2.9)$ \\
\hline \multicolumn{3}{|l|}{ Education $(\%)$} \\
\hline & Primary of below & $13(12.7)$ \\
\hline & Secondary junior & $8(7.8)$ \\
\hline & Secondary senior & $39(38.2)$ \\
\hline & University or above & $40(39.2)$ \\
\hline \multicolumn{3}{|l|}{ Occupation (\%) } \\
\hline & Housewife & $18(17.6)$ \\
\hline & Professional & $24(23.5)$ \\
\hline & Clerical & $21(20.6)$ \\
\hline & Labour & $4(3.9)$ \\
\hline & Service & $13(12.7)$ \\
\hline & Unemployed & $5(4.9)$ \\
\hline & Student & $4(3.9)$ \\
\hline & Others & $11(10.8)$ \\
\hline \multicolumn{2}{|c|}{ Health care worker $(\%)$} & $18(17.5)$ \\
\hline \multicolumn{2}{|c|}{ Amoy garden residents (\%) } & $39(38.2)$ \\
\hline \multicolumn{3}{|c|}{ Religion (\%) } \\
\hline & Buddhism & $15(14.7)$ \\
\hline & Taoist & $1(1)$ \\
\hline & Islam & $1(1)$ \\
\hline & Christian & $14(13.7)$ \\
\hline & Catholic & $4(3.9)$ \\
\hline & Others/none & $67(65.7)$ \\
\hline \multicolumn{2}{|c|}{ Family members had SARS (\%) } & $27(26.5)$ \\
\hline \multicolumn{2}{|c|}{ Family members died of SARS (\%) } & $8(7.8)$ \\
\hline \multicolumn{2}{|c|}{ Neighbours/friends died of SARS (\%) } & $11(10.8)$ \\
\hline \multicolumn{2}{|c|}{ History of mental illness (\%) } & $2(2)$ \\
\hline \multicolumn{2}{|c|}{ History of chronic disease $(\%)$} & $10(9.8)$ \\
\hline
\end{tabular}

for 10-14 days. Different forms of corticosteroids, including hydrocortisone, prednisolone and methylprednisolone, were given in various dosages. About half of patients received pulse methylprednisolone at 500-1000 mg per dose. Apart from ribavirin and corticosteroids, all patients received potent antibiotics for empirical treatment. Antibiotics commonly used included extended spectrum penicillins, macrolides, fluoroquinolones and aminoglycosides.

\subsection{Neuropsychiatric symptoms at acute and convalescent phases}

As presented in Table 3, neuropsychiatric complaints were common at both acute and convalescent phases. In the analysis, only those answered 2 or 3 were regarded as 'Yes' for that item. Most of the common complaints, like poor concentration, memory, insomnia and tension, were consistent with anxiety and depression. A high proportion of time disorientation could suggest delirium, and psychotic symp-
Table 2

Clinical variables of SARS survivors

\begin{tabular}{ll}
\hline $\begin{array}{l}\text { Clinical } \\
\text { variables }\end{array}$ & $N=102$ \\
\hline SARS symptoms (mean \pm S.D.) & $8.8 \pm 4.7$ \\
Dyspnoea (\%) & $15(14.7)$ \\
Respiratory rate (mean \pm S.D.) & $18.9 \pm 2.2$ \\
Initial oxygen saturation (mean \pm S.D.) & $96.9 \pm 2.0$ \\
Maximum oxygen requirement (\%) & \\
$\quad$ Nil & $56(60.2)$ \\
$\quad<21 /$ min & $19(20.4)$ \\
$\quad 3-51 /$ min & $5(5.4)$ \\
$\quad 6-101 /$ min & 0 \\
$\quad>101 /$ min & $13(14)$ \\
Chest radiograph on admisson & \\
$\quad$ Clear & $8(7.9)$ \\
$\quad$ Unilateral involvement & $78(77.3)$ \\
$\quad$ Bilateral involvement & $15(14.8)$ \\
ICU care (\%) & $10(9.8)$ \\
Mechanical ventilation (\%) & $3(2.9)$ \\
Pulse steroid (\%) & $45(44.1)$ \\
Total dosage of pulse steroid in prednisone & $2500(2342.8,5000.0)$ \\
equivalent (mg)(median and quartile) & \\
Accumulated dosage of corticosteroid in pred- & $1662.5(941.3,3960.0)$ \\
nisone equivalent (mg) during acute phase \\
(median and quartile)
\end{tabular}

toms were reported by a few. A decrease in prevalence at convalescent phase was noticed in most of the checklist items except poor memory, which persisted at high level of $43 \%$. There was a higher degree of optimism among patients at convalescent phase.

\subsection{Factors associated with neuropsychiatric complaints in acute phase}

Severity of SARS and the corticosteroids were significantly associated with anxiety depression, psychosis and behavioural problems in acute phase (Table 4). Health care workers had more anxiety-depression in univariate analysis, but the effect was not significant after controlling for covariates. Nevertheless, health care worker still had more cognitive problems at shown in our regression model, but they seemed to be protected from psychosis. All together, our model predicted $52 \%$ of the observed variance in anxietydepression and $33 \%$ in psychosis. Individually, effects of disease, corticosteroids and social factors accounted for $29.9 \%, 2.9 \%$ and $18 \%$, respectively of the observed variances in anxiety-depression, and $11 \%, 3.1 \%$ and $15.7 \%$ of the observed variances in psychosis at acute phase.

\subsection{Factors associated with neuropsychiatric complaints in convalescent phase}

In the convalescent phase, the factors were less influential as the best model only predicted $33 \%$ of the observed varian- 
Table 3

Prevalence of symptoms on NPSC items. A score of 2 or 3 was regarded 'Yes' for the item

\begin{tabular}{|c|c|c|c|c|c|}
\hline Symptoms & $\begin{array}{l}\text { Prevalence }(\%) \\
\text { at acute phase }\end{array}$ & $\begin{array}{l}\text { Prevalence }(\%) \\
\text { at convalescent phase }\end{array}$ & Symptoms & $\begin{array}{l}\text { Prevalence }(\%) \\
\text { at acute phase }\end{array}$ & $\begin{array}{l}\text { Prevalence }(\%) \\
\text { at convalescent phase }\end{array}$ \\
\hline Poor concentration & 38.2 & 26.5 & Suicidal idea & 2.0 & 0 \\
\hline Impaired memory & 41.2 & 43.1 & Crying spell & 23.5 & 13.7 \\
\hline Disoriented in time & 33.3 & 7.8 & Irritability/yelling & 4.9 & 3.9 \\
\hline Disoriented in place & 3.9 & 3.0 & Fear and panic & 26.5 & 13.7 \\
\hline Pressured speech & 20.6 & 11.8 & Tension & 36.3 & 20.6 \\
\hline Euphoric mood & 7.8 & 10.8 & Auditory hallucination & 3.9 & 1.0 \\
\hline Unstable mood & 29.4 & 23.5 & Visual hallucination & 2.0 & 0 \\
\hline Overly optimistic & 14.7 & 16.7 & Persecutory ideas & 3.9 & 2.0 \\
\hline Pessimistic thinking & 27.5 & 14.7 & Aggressive behaviors & 0 & 1.0 \\
\hline Insomnia & 46.1 & 22.5 & Abscondence & 3.0 & 1.0 \\
\hline Low mood & 36.3 & 18.6 & Noncompliance & 3.0 & 2.9 \\
\hline Social isolation & 19.6 & 4.9 & Self-injurious behaviors & 0 & 1.0 \\
\hline Reticent and wordless & 25.5 & 7.8 & & & \\
\hline
\end{tabular}

Table 4

Factors contributing to neuropsychiatric symptoms at acute phase, multiple linear regression analysis using factors scores in each construct as dependent variables

\begin{tabular}{|c|c|c|c|c|c|c|c|c|c|c|}
\hline Constructs & $\mathrm{R}^{2}$ & P-value & Disease & $\operatorname{Std} \beta$ & Steroids & $\operatorname{Std} \beta$ & Social & $\operatorname{Std} \beta$ & Miscellaneous & $\operatorname{Std} \beta$ \\
\hline \multirow[t]{4}{*}{ Anxiety-depression } & 0.52 & $<0.01$ & SARS sym & 0.42 & TPS & 0.24 & Housewife & 0.24 & Age & -0.20 \\
\hline & & & DOS-acute & 0.20 & & & Professional & 0.17 & & \\
\hline & & & & & & & Labour & 0.19 & & \\
\hline & & & & & & & N/F DSARS & -0.20 & & \\
\hline \multirow[t]{2}{*}{ Psychosis } & 0.33 & $<0.01$ & $0_{2}>101 / \mathrm{min}$ & 0.27 & PS & 0.16 & $\mathrm{HCW}$ & -0.20 & & \\
\hline & & & SARS sym & 0.35 & & & Fam. DSARS & 0.23 & & \\
\hline Cognition & 0.31 & $<0.01$ & SARS sym & 0.35 & & & $\mathrm{HCW}$ & 0.24 & Mental illness & 0.25 \\
\hline Positive altitude & 0.15 & $<0.01$ & SARS sym & -0.28 & & & Fam. Supp. & 0.30 & & \\
\hline Behavioural symptoms & 0.09 & 0.02 & $\mathrm{SaO}_{2}$ & -0.21 & TPS & 0.19 & & & & \\
\hline Mania & 0.08 & $<0.01$ & $\mathrm{SaO}_{2}$ & 0.28 & & & & & & \\
\hline
\end{tabular}

SARS sym, SARS symptoms; DOS-acute, duration of stay in acute hospital; $\mathrm{SaO}_{2}$, oxygen saturation; TPS, total dose of pulse steroid; PS, use of pulse steroid, N/F DSARS, neighbour/friend died of SARS; HCW, health care worker; Fam. DSARS, family member died of SARS, Fam. Supp., family support; Mental illness, history of mental illness.

Table 5

Factors contributing to neuropsychiatric symptoms at convalescent phase, multiple linear regression analysis using factors scores in each construct as dependent variables

\begin{tabular}{|c|c|c|c|c|c|c|c|c|c|c|}
\hline Constructs & $R^{2}$ & $P$-value & Disease & Std $\beta$ & Steroids & $\operatorname{Std} \beta$ & Social & $\operatorname{Std} \beta$ & Miscellaneous & Std $\beta$ \\
\hline Anxiety-depression & 0.33 & $<0.01$ & SARS sym & 0.33 & TPS & 0.29 & $\begin{array}{l}\text { HCW } \\
\text { N/F DSARS } \\
\text { Fam. DSARS }\end{array}$ & $\begin{array}{l}0.22 \\
-0.20 \\
0.26\end{array}$ & Mental illness & 0.18 \\
\hline Cognition & 0.27 & $<0.01$ & $\begin{array}{l}\text { CXR-B } \\
\text { SARS sym }\end{array}$ & & & & $\begin{array}{l}\text { Student } \\
\text { Fam. SARS }\end{array}$ & $\begin{array}{l}0.34 \\
0.24\end{array}$ & Male & -0.16 \\
\hline Mania & 0.23 & $<0.01$ & & & & & & & & \\
\hline $\begin{array}{l}\text { Positive psychological. } \\
\text { well-being }\end{array}$ & 0.16 & $<0.01$ & $\begin{array}{l}\mathrm{SaO}_{2} \\
\mathrm{CXR}-\mathrm{B}\end{array}$ & $\begin{array}{l}0.19 \\
-0.22\end{array}$ & $\mathrm{TS}$ & -0.22 & & & & \\
\hline
\end{tabular}

SARS sym, SARS symptoms; CXR-B, bilateral involvement on CXR; $\mathrm{SaO}_{2}$, oxygen saturation; TPS, total dose of pulse steroid; TS, total(accumulated) dose of steroid; HCW, health care worker; N/F DSARS, neighbour/friend died of SARS; Fam. DSARS, family member died of SARS; Fam. SARS, family member had SARS; Mental illness, history of mental illness.

ces in anxiety-depression (Table 5). Noteworthy, effect of corticosteroids persisted in the convalescent period and was identified as a risk factor against psychological well-being. Being health care workers, which was not an independent risk factor for anxiety-depression at acute phase, became a risk factor at convalescence. Corticosteroids and being health care workers accounted for $5.1 \%$ and $2.8 \%$, respectively of the observed variances in anxiety depression.

\section{Discussion}

\subsection{Limitations of the study}

This study was a retrospective data collection relied on recalls from patients. The valid response rate at $33 \%$ was not high in a mail questionnaire survey. We learnt that at least four other studies were carried at the same time, and some 
patients did not want to join too many different studies. The age distribution and proportion of health care workers in our replied sample were similar to the Hong Kong cohort [25], but the male gender was underrepresented in our sample (34.3\% in the sample vs. $44.3 \%$ in Hong Kong cohort). We did not have a good reason to explain this difference. In a post hoc survey on the utilization of clinical psychology service by SARS patients, we found our study sample was comparable to non-responders as well as the Hong Kong cohort, suggesting a similar psychological outcome. We believed our sample was representative of the Hong Kong SARS. We admitted difficulty in assessing the accuracy of information collected, although the worry was partially offset by the good item correlation in the family valued answers. The pattern of correlation, in which easily observed symptoms were better correlated than the difficult ones, suggested an independent rating in the questionnaires.

\subsection{Disease severity, corticosteroids, social factors and neuropsychiatric outcomes}

We focused on the modifying effects of disease, corticosteroids and social factors on neuropsychiatric complaints in SARS patients. Many of the anxiety-depression symptoms were adjustment reactions during acute stage of illness, and some of the symptoms like insomnia and poor concentration could also represent posttraumatic stress disorder (PTSD) which was expected to be common in this epidemic. Although we did not have information on psychological well being in the community during the epidemic as a control, our findings did show an impact from the factors we studied on the neuropsychiatric symptoms, both at acute and convalescent phases. Our patients were treated in isolation settings and had lots of uncertainties on their health. These were similar to patients treated in ICU where many have developed PTSD as a result $[10,11]$. We believed these constituted the main unmeasured variances and might also explain the inability of our questionnaire to show up the ICU impact.

Non-human coronaviruses like the mouse hepatitis virus in rats and haemagglutinating encephalomyelitis virus in pigs could cause demyelination and central nervous system (CNS) infections [17]. Since the new SARS associated coronavirus (SARS-CoV) was postulated to be originated from animals [9], direct involvement of nervous system in SARS was not impossible. Although clinical encephalitis was not seen in our patients, the virus had been identified in the cerebrospinal fluid [12]. We could not exclude a possible direct role of SARS-CoV in the neuropsychiatric symptoms we described.

Neuropsychiatric symptoms after a non-CNS viral infection were uncommon. The most frequently described neuropsychiatric problem after a viral infection was chronic fatigue syndrome (CFS), which also shared symptoms of anxiety and depression $[6,23]$. Our survey method could not distinguish CFS from other psychiatric diagnosis. We believed some of our patients might suffer CFS, especially if their symptoms persisted.
Previous reports suggested a high prevalence of dose related steroid effect on mental problems [2,14,15,20]. Since most of our patients had been given high dose corticosteroids, and there was no control group for comparison, its relative importance would be underestimated. Despite this restriction we still demonstrated a significant effect of corticosteroids especially on anxiety-depression in both phases, which was consistent with previous work that $80 \%$ of the steroid induced psychiatric disturbances were affective symptoms [2].

Our affected health care workers had more anxietydepression after recovering from SARS. Health care professionals were well known to be among the group of high occupational stress [13]. They were prone to develop overt psychological reactions under great stress like massive casualties $[1,24]$. In fact many unaffected staffs were carried away with unhappy memories during the epidemic. Many recovering health care workers still had problem of confidence and role adjustments. Some felt guilty on transmitting the disease to their families, and some staffs found themselves being isolated from other colleagues. They also worried about potential occupational hazards in the future, compensation issues, insurances, new hospital policies, etc. To address the importance of psychological health, the hospital has incorporated psychology sessions in the newly implemented infection control trainings. We encouraged psychology modules in medical and nursing schools, and consultation services should be easily assessable by all frontline medical staffs.

Our preliminary finding on a high prevalence of memory impairments at convalescence would need further confirmation. It could be steroid related. Through its effect on hippocampal metabolism, a big dose of exogenous steroid could induce reversible memory impairments as shown both in healthy subjects [16] and in treatment of multiple sclerosis patients [19]. Chronic stimulation in the case of Cushing's disease could cause atrophy of the hippocampus [27]. Poor memory could also be a symptom of CFS which frequently accompanied with viral infections [6]. Adrenal insufficiency after steroid withdrawal is another possibility, especially when both the dosage was high and the duration was long. Further study is definitely required.

\section{Conclusion}

Our study suggested severity of SARS, high dose corticosteroids and being health care workers were independent predictors of neuropsychiatric complaints in both acute and convalescent phases.

\section{Acknowledgments}

The authors were indebted to Dr. Chee Wing Wong and Dr. Yin Kwok Ng from Kwai Chung Hospital who gave us invaluable comments in conducting this study. This study 
could not be possible without the strong support from Dr. Eugene Yuk Keung Tso, Dr. Owen Tak Yin Tsang, Dr. Kin Wing Choi and Dr. Wing Lok Tong from Princess Margaret Hospital and also Dr. Kuen Lam from Caritas Medical Centre. We would express our highest respect to all staffs from Department of Medicine and Geriatrics as well as the Department of Intensive Care of Princess Margaret Hospital, and also to many doctors from government and private sector who volunteered to fight against SARS during the epidemic in 2003.

\section{Appendix}

SARS neuropsychiatric symptoms checklist

Filled in by recovered SARS patients. During the period of hospitalization, you may have the following symptoms. Please indicate the frequency of each symptom with following scale:

$0=$ Not present

$1=$ Sometimes

$2=$ Often

3 = Always

1. Poor concentration

2. Impaired memory

3. Disoriented in time

4. Disoriented in place

5. Pressured speech

6. Euphoric mood

7. Unstable mood

8. Overly optimistic

9.Pessimistic thinking

10. Insomnia

11. Low mood

12. Social isolation

13. Reticent and wordless

14. Suicidal idea

15. Crying spell

16. Irritability/ yelling

17. Fear and panic

18. Tension

19. Auditory hallucination

20. Visual hallucination

21. Persecutory ideas

22. Aggressive behaviors

23. Abscondance

24. Noncompliance

25. Self-injurious behaviors

SARS Neuropsychiatric Symptoms Checklist

Filled in by recovered SARS patients. After discharge from hospital and cessation of steroid, you may have the following symptoms. Please indicate the frequency of each symptom with following scale:

$$
\begin{aligned}
& 0=\text { Not present } \\
& 1=\text { Sometimes }
\end{aligned}
$$

$2=$ Often

3 = Always

1. Poor concentration

2. Impaired memory

3. Disoriented in time

4. Disoriented in place

5. Pressured speech

6. Euphoric mood

7. Unstable mood

8. Overly optimistic

9. Pessimistic thinking

10. Insomnia

11. Low mood

12. Social isolation

13. Reticent and wordless

14. Suicidal idea

15. Crying spell

16. Irritability/ yelling

17. Fear and panic

18. Tension

19. Auditory hallucination

20 . Visual hallucination

21. Persecutory ideas

22. Aggressive behaviors

23. Abscondance

24. Noncompliance

25. Self-injurious behaviors

\section{References}

[1] Alexander DA, Klein S. Ambulance personnel and critical incidents: impact of accident and emergency work on mental health and emotional well-being. Br J Psychiatry 2001;178:76-81.

[2] Boston Collaborative Drug Surveillance Program. Acute adverse reactions to prednisone in relation to dosage. Clin Pharmacol Therap 1972;13:694-8.

[3] Chan DW, Chan TSC. Reliability, validity and the structure of the General Health Questionnaire in a Chinese contest. Psychological medicine 1983;13:363-71.

[4] Chan-Yeung M, Yu WC. Outbreak of severe acute respiratory syndrome in Hong Kong Special Administrative Region: case report. BMJ 2003;326:850-2.

[5] Cheng SKW, Tsang JSK, Ku KH, Wong CW, Ng KY. Psychiatric complications in patients with severe acute respiratory syndrome (SARS) during the acute treatment phase: a series of 10 cases. Br J Psychiatry 2004;184:359-60.

[6] Christodoulou C, De Luca J, Lange G, Johnson SK, Sisto SA, Korn L, et al. Relation between neuropsychological impairment and functional disability in patients with chronic fatigue syndrome. J Neuro Neurosurg Psychiatry 1998;64:431-4.

[7] Crocker L, Algina J. Factor analysis in Introduction to classical and modern test theory. Wadsworth Group; 1986.

[8] Cronbach LJ. Coefficient alpha and the internal structure of tests. Psychometrika 1951;16:297-334.

[9] Guan Y, Zheng BJ, He YQ, Liu XL, Zhuang ZX, Cheung CL, et al. Isolation and characterization of virus related to the SARS coronavirus from animals in southern China. Science 2003;302:276-8.

[10] Jones C, Griffiths RD, Humphris G, Skirrow PM. Memory, delusions, and the development of acute posttraumatic stress disorder-related symptoms after intensive care. Crit Care Med 2001;29:573-80. 
[11] Kapfhammer HP, Rothenhausler HB, Krauseneck T, Stoll C, Schelling G. Posttraumatic stress disorder and health-related quality of life in long-term survivors of acute respiratory distress syndrome. Am J Psychiatry 2004;161:45-52.

[12] Lau KK, Yu WC, Chu CM, Lau ST, Sheng B, Yuen KY. Possible central nervous system infection by SARS coronavirus. Emerg Infect Dis 2003;10:342-4.

[13] Laposa JM, Alden LE, Fullerton LM. Work stress and posttraumatic stress disorder in ED nurses/personnel. J Emerg Nurs 2003;29:23-8.

[14] Ling MH, Perry PJ, Tsuang MT. Side effects of corticosteroid therapy: psychiatric aspects. Arch Gen Psychiatry 1981;38:741-7.

[15] Lewis DA, Smith RE. Steroid-induced psychiatric syndromes: a report of 14 cases and a review of the literature. J Affective Disord 1983;5:319-32.

[16] Lupien SJ, Gillin CJ, Hauger RL. Working memory is more sensitive than declarative memory to the acute effects of corticosteroids: a dose-response study in humans. Behav Neurosci 1999;113:420-30.

[17] Monto AS. Coronaviruses. In: Evans AS, editor. Viral infections of humans epidemiology and control, 3rd ed. New York: Plenum Press; 1989.p. 153-67.

[18] Munro BH. Statistical methods for health care research. 4th ed. Philadelphia: J.B.Lippincott Company; 2002.

[19] Oliveri RL, Sibilia G, Valentino P, Russo C, Romeo N, Quattrone A Pulsed methylprednisolone induces a reversible impairment of memory in patients with relapsing-remitting multiple sclerosis. Acta Neurol Scand 1998;97:366-9.
[20] Patten SB, Neutel CI. Corticosteroid-induced adverse psychiatric effects: incidence, diagnosis and management. Drug Saf 2000;22: 111-22.

[21] Peiris JS, Lai ST, Poon LLM, Guan Y, Yam LY, Lim W, et al. Coronavirus as a possible cause of severe acute respiratory syndrome. Lancet 2003;361:1319-25.

[22] Rota PA, Oberste MS, Monroe SS, Nix WA, Campagnoli R, Icenogle JP, et al. Characterization of a noval coronavirus associated with severe acute respiratory syndrome. Science 2003;300:1394-9.

[23] Sabin TD. An approach to chronic fatigue syndrome in adults. The Neurologist 2003;9:28-34.

[24] Sabin-Farrell R, Turpin G. Vicarious traumatization: implication for the mental health of health care workers? Clinical Psycho Rev 2003; 23:449-80.

[25] SARS expert committee. SARS in Hong Kong: from experience to action. Hong Kong Special Administrative Region. 2003. http: //www.sars-expertcom.gov.hk/eindex.html

[26] SPSS Professional Statistics 6.1. Chicago, IL: SPSS Inc; 1994.

[27] Starkman MN, Giordani B, Berent S, Schork A, Schteingart DE. Elevated cortisol levels in Cushing's disease are associated with cognitive decrements. Psychosom Med 2001;63:985-93.

[28] World Health Organization. Severe acute respiratory syndrome (SARS): status of the outbreak and lessons for the immediate future. Geneva, 20 May 2003 